\title{
A Complexidade do Tempo Geológico e a sua Aprendizagem com Alunos Portugueses (12-13 anos)
}

\author{
Jorge Bonito ${ }^{1}$, Dorinda Rebelo ${ }^{2}$, Margarida Morgado ${ }^{3}$, Graça Monteiro ${ }^{4}$, Jorge Medina ${ }^{5}$, \\ Luís Marques ${ }^{6}$, Luísa Martins ${ }^{7}$ \\ ${ }^{1}$ Depto. de Pedagogia e Educação da Univ. de Évora, Portugal. jbonito@uevora.pt \\ 2 Escola Secundária de Estarreja, Portugal. dorinda.rebelo@netvisao.pt \\ ${ }^{3}$ Escola Secundária de Viriato de Viseu, Portugal. morgadommargarida@gmail.com \\ 4 Escola Secundária de Alcides de Faria, Portugal. gracamonteiro88@hotmail.com \\ ${ }^{5}$ Depto. de Geociências da Universidade de Aveiro, Portugal. jmedina@ua.pt \\ ${ }^{6}$ Centro de Investigação Didáctica e Tecnologia na Formação de Formadores da \\ Universidade de Aveiro, Portugal. luis@ua.pt \\ ${ }^{7}$ Escola Secundária de Alves Martins de Viseu, Portugal. luisalopesmartins@gmail.com
}

\begin{abstract}
THE COMPLEXITY OF GEOLOGICAL TIME AND LEARNING BY K-12/13 PORTUGUESE STUDENTS OF GEOLOGY. This paper is a contribution towards an in-depth reflection about the philosophical and scientific dimensions of the complex concept of time. "This reflection is bored on the assumfition that a broad view of this issue is needed for a"deeper research on teaching and learning of this topic. Therefore, data related to the perceptions of Portuguese students, 12/13 years of this age, are presented; these perceptions are mainly concerned with the characteristics which supposed influence the understanding of the concept of time. The relevance given by the students to the concept in the context of geological contents learning is also under analysis. The study is being developed within the research Project Deep time in schooling: contributions of students' perceptions for the development of scientifically literate citizens in the Research Centre for Didactics and Technology in Teacher Education, with the participation of researchers from the Universities of Aveiro and Évora and secondary school science teachers. Citation: Bonito J., Rebelo D., Morgado M. da, Monteiro G., J. Medina, Marques L., Martins L. , Louro M. 2011. A Complexidade do Tempo Geológico e a Aprendizagem em Geologia de Alunos Portugueses (12-13 anos). Terræ Didatica, $7(1): 63-76<$ <ttp://www.ige.unicamp.br/terraedidatica/>
\end{abstract}

\section{KEYWORDS Deep time, complexity, students' perceptions, basic education}

RESUMO Este artigo pretende contribuir para a reflexão sobre o complexo conceito de tempo, nas suas vertentes filosófica e científica, reconhecendo-se a consequente necessidade de proceder ao aprofundamento da investigação no âmbito do ensino e da aprendizagem desta temática. Os resultados encontrados sobre concepcões de alunos do $3 .^{\circ}$ Ciclo do Ensino Básico ${ }^{1}$ permitem perceber a importante valorização que atribuem ao conceito de Tempo Geológico na aprendizagem da Geologia, apesar de não existir acerca dele uma perspectiva adequada. Entre outros resultados, as dificuldades sentidas recaem no facto deste conceito ser complexo, o que dificulta a compreensão de fenómenos geológicos e da história da Terra, sendo, por isso, considerado pelo alunos dispensável na aprendizagem da Geologia. O trabalho insere-se no Projecto Deep time in schooling: contributions of students' perceptions for the development of scientifically literate citizens, que se desenvolve no Centro de Investigação Didáctica e Tecnologia na Formação de Formadores, da Universidade de Aveiro (Portugal), envolvendo investigadores em Geologia e em Didáctica das Ciências das universidades portuguesas de Aveiro e de Évora e professores de Biologia e Geologia de várias escolas públicas dos Ensinos Básico e Secundário

PALAVRAS-CHAVE Tempo geológico, complexidade, concep̧ões de alunos, ensino básico

${ }^{1} 0$ 3. ${ }^{\circ}$ Ciclo do Ensino Básico Português compreende três níveis de escolaridade, correspondentes a alunos com idades entre os 12 e os 15 anos. No caso concreto desta investigação, 0 estudo empírico realizado integra alunos com 12-13 anos de idade. 


\section{Acerca do projecto e do artigo}

O projecto de investigação que enforma este artigo tem como objectivos: a) identificar factores sociais e cognitivos que influenciam as concepções sobre Tempo Geológico; b) analisar o modo como o ambiente físico de uma pessoa afecta as suas concepções e a sua conceptualização em relação ao conceito de Tempo Geológico; c) desenvolver um quadro teórico que permita compreender as concepções sobre Tempo Geológico; d) apresentar sugestões para desenvolvimento de estratégias e de materiais curriculares capazes de influenciar as concepções dos alunos sobre a história da Terra; e) fornecer condições que permitam reconhecer que há tópicos das Ciências da Terra que assumem um papel relevante no desenvolvimento de cidadãos cientificamente literados.

$\mathrm{O}$ artigo remete para uma reflexão sobre a natureza do conceito de tempo, detalhando as suas vertentes filosófica e científica, e reconhecendo-se a consequente necessidade de proceder ao aprofundamento da investigação no âmbito do ensino e da aprendizagem desta temática. Apresenta-se um estudo empírico realizado com alunos do $3 .^{\circ}$ Ciclo do Ensino Básico de escolas públicas portuguesas, que diagnostica as respectivas concepções acerca da temática em apreciação. Por fim, faz-se referência aos indicadores obtidos e às implicações dos mesmos ao nível da formação contínua dos professores responsáveis pela leccionação de temas de Geociências, traduzindo-se na conceptualização, na organização e no acompanhamento do processo de ensino da temática curricular - Tempo Geológico.

\section{A complexidade e subjectividade do conceito de tempo e sua relevância curricular}

A noção de tempo é uma função da consciência (Freud 1974), familiar para cada um de nós; a experiência comum parece suficiente para jamais duvidarmos da sua existência. Por um lado, para o senso comum é difícil haver noção tão óbvia como a de tempo, já que o podemos quantificar ou nele efectuar previsões do quotidiano e separálo cronologicamente em ontem, hoje e amanhã (tempo objectivo). Segundo Loewald (citado em Pereira 1998), mesmo estas noções são estáticos conceitos lineares - "são aspectos do sentido do tempo que formam cada um e são constantemen- te influenciados por forças intrapsíquicas” (p. 83). Podemos questionar se a quantificação do tempo não corresponde à sua própria dissimulação, por detrás de uma mobilidade absolutamente regular. O sentido do tempo está associado à consciência das percepções internas da passagem efémera das nossas vidas, e com o desenvolvimento da consciência projectamos estas percepções internas para o exterior, chamando a isso tempo.

Será difícil enfrentar maior complexidade do que a que encontramos quando nos afoitamos a clarificar a natureza do tempo. Já no século IV, Santo Agostinho dedica o Livro Onze das Confissões ao "Homem e o Tempo", sobressaindo a célebre análise filosófica sobre a essência do tempo, questão ainda hoje obscura e controversa. Santo Agostinho estudou o tempo sob o aspecto psicológico. É conhecida a sua posição referindo: "o que é, por conseguinte, o tempo? Se ninguém mo perguntar, eu sei; se o quiser explicar a quem me fizer a pergunta, já não sei” (Livro XI, 14). Freud (1974) defendeu que o sentido do tempo não é uma capacidade inata, mas antes se desenvolve de comum acordo com a consciência, aquilo que Prigogine (1990) designou por "seta psicológica do tempo".

A natureza do tempo, isto é, o seu estatuto ontológico, a sua relação com o espaço e a sua cognoscibilidade é, sem dúvida, um dos núcleos centrais do pensamento filosófico sendo, porventura, lícito assinalar que toda a ontologia clássica se traduziu numa filosofia do tempo. Também o discurso científico manifesta preocupações com a reflexão sobre o tempo, servindo este de ligação entre os pensamentos filosófico e científico, tendo os principais analistas estado preocupados e interessados no sentido subjectivo do tempo.

A reflexão sobre esta temática é já encontrada nos filósofos pré-socráticos, os quais articulavam a pergunta sobre a totalidade da existência com o tempo que é, afinal, o elemento que impõe a ordem e que nos transporta às origens. $\mathrm{Na}$ filosofia de $\mathrm{Pla}-$ tão(428-348), o tempo - a imagem móvel da eternidade imóvel (Klein 2007) - desenvolve-se em ciclo, tendo subjacente a periodicidade das marés, os solstícios ou as estações do ano. Em Aristóteles(384-322), a eternidade platónica é expressa com o suceder do tempo - o número do movimento de acordo com o antes e o depois (Klein 2007).

Com a revolução científica emerge uma concepção de tempo substancialmente distinta (Coveney \& Highfield 1992), defendendo-o Galileo 
Galilei numa perspectiva abstracta, vista como um parâmetro que vale para todo o tipo de movimento e não só para o uniforme como pensava Aristóteles. É desta forma que tempo, espaço e matéria passam a ser os três grandes conceitos da física moderna clássica - o mecanicismo. A análise do tempo passa a ser centrada num contexto físico e visto como uma realidade transcendente ou como uma relação.

Para Newton, o tempo perde esta transcendência, fluindo sem relação com nada exterior. Tempo e espaço não são mais meras categorias dos corpos, mas são independentes deles e movem-se no respectivo contexto. O carácter absoluto do tempo em Newton é dominante na filosofia moderna, inclusive de Kant que, contudo, introduz nova inflexão no modo de considerar a situação - a completa independência do tempo em relação às coisas que nele ocorrem. Aristóteles e Newton acreditavam no tempo absoluto. Consideravam que poderia ser medido sem incerteza o intervalo de tempo entre dois acontecimentos, e que o tempo era completamente separado e independente do espaço.

Com Einstein, o tempo passa a ser visto como estando afectado pela matéria e energia, podendo ser como que manipulado, abandonando-se a ideia de tempo absoluto. $\mathrm{Na}$ feliz expressão de Klein (2007) “... o tempo físico perdeu um pouco da sua suposta pureza e muito da sua independência: reencontrou-se inseparavelmente ligado ao espaço, associado à energia, ancorado na matéria (p. 9), formando um objecto designado espaço-tempo. Sabemos que em campos gravitacionais fortes e para observadores em movimento, o fluxo do tempo é condicionado pela massa e pela energia nela contida e daí a posição einsteiniana:

every reference-body has its own particular time; unless we are told the reference-body to which the statement of time refers, there is no meaning in a statement of the time of an event (Einstein 1905, citado Yousef 2008, p. 22).

Segundo Hawking (1988), "um acontecimento passa a ser qualquer coisa, que ocorre num determinado ponto do espaço e num determinado momento" (p. 52), especificado por quatro coordenadas (três coordenadas do espaço e uma do tempo) - espaço quadrimensional.

Reconhecendo embora todo o esforço de aprofundamento efectuado, no âmbito da filosofia, e da ciência, continuam por responder questões centrais como, por exemplo: O que é, de facto, o tempo presente, uma vez que o passado já não existe e o futuro ainda não veio? Parece que só o presente existe, contudo, o presente o que é senão esse contínuo trânsito do futuro para o passado, do ainda não para o já não? Qual a relação entre o tempo e o universo? Terá o tempo começado com o Big Bang? E em que consiste afinal o tempo que flui, o qual se não altera, mas que faz com que tudo se altere? Qual a verdadeira relação do tempo com as coisas? Qual a razão por que o tempo possui um sentido? Que convergências existem entre o tempo físico e o tempo vivido? Existe um tempo, ou vários tempos ao mesmo tempo? Como nos diz Pereira (1988), a junção da relatividade geral à mecânica quântica para a compreensão do universo pode sugerir que o "chamado tempo imaginário é realmente o tempo verdadeiro e aquilo a que chamamos tempo real é produto da nossa imaginação" (p. 101).

Independentemente da oportunidade das interrogações, o ser humano tem vindo a procurar conviver com o tempo através das percepções sobre ele desenvolvidas - tempo subjectivo, determinado por forças dinâmicas de psiquismo, sendo pessoal e experiencial - estabelecendo, no interior do próprio tempo, múltiplas variedades (tempo para pensar, tempo para intervir, tempo para partilhar, tempo para ser, ...). Carrière (1999) considera que "é bem possível que a nossa época seja o tempo em que os tempos que inventámos estejam a desaparecer, sem que saibamos decidir se é bom ou mau que assim aconteça” (p. 145). Curiosamente, a expressão anglo-saxónica deep time está centrada no entendimento de que o Universo existe desde há muito, enquanto o aparecimento da humanidade se confina aos últimos segundos do metafórico relógio geológico, tendo esta situação implicações ao nível da Cosmologia, da Biologia e, obviamente, das Ciências da Terra. Isto não deixa de contribuir, também, para o nível de uma cultura de intervenção do aluno, tendente ao desenvolvimento de uma cidadania mais consciente. Por exemplo, os actuais debates sobre problemas ambientais têm cada vez mais presente a perspectiva temporal em relação à ocorrência de acontecimentos como sejam o aquecimento (ou arrefecimento) global e a alteração do nível do mar (Trend 2005). Assim, intervir para o "bem-estar" do planeta Terra passa pela compreensão da escala temporal em que os fenómenos que o afectam ocorrem e da necessidade de se actuar em tempo útil se queremos preservá-lo. 
No entanto, a abordagem curricular do conceito de tempo assume, também, um papel relevante no desenvolvimento de uma cidadania mais exigente.

A complexidade da temática do tempo estende-se à Educação em Ciência, particularmente à Educação em Geologia, o que torna compreensível o número de estudos (Bonito et al.2011; in press; Escribano Ródenas 2008, Dodick \& Orion 2003, Marques \& Thompson 1997) que neste domínio têm vindo a ser efectuados. Eles indicam que a abordagem do tempo é tarefa cognitivamente aliciante, porque complexa e exigindo uma atitude de pesquisa sistemática, reconhecendo-se a difícil apropriação, por parte dos alunos, do conceito de Tempo Geológico. Ao nível da Educação em Geologia, a abordagem do conceito de tempo e o reconhecimento da sua imensidão é fundamental para enriquecer um pensamento que permita compreender o impacto que têm os imperceptíveis e lentos processos, ao nível de mudanças profundas como, por exemplo, sucede no âmbito da geomorfologia.

\section{Procedimentos metodológicos - elaboração e administração de um questionário}

O estudo exploratório de natureza procurando compreender as concepções de alunos do $7 .^{\circ}$ ano de escolaridade (12-13 anos) sobre o conceito de tempo. O questionário foi um instrumento adequado para a recolha de informação considerando o tamanho da amostra e os objectivos formulados. A partir da pesquisa bibliográfica efectuada (Trend 2005, Dodick \& Orion 2003) e da própria reflexão dos investigadores, estabelecemos um enquadramento que conduziu às seguintes fases: a) conceptualização e definição de objectivos, apresentados na Tabela I; b) elaboração de questões abertas, fechadas e de estimação; c) validação do questionário, junto de um painel de juízes; e d) implementação do questionário num estudo piloto.

O estudo principal foi desenvolvido com recurso a uma amostra constituída por 432 alunos, distribuídos por 21 escolas do ensino público português com 3. ${ }^{\circ}$ Ciclo do Ensino Básico, da zona Centro e Norte de país, pertencentes a 15 municípios. De modo a efectuar a análise dos resultados obtidos, foram criadas as categorias de conteúdo que se encontram indicadas na Tabela I. A construção destas categorias teve em conta: os conceitos de idade relativa e absoluta; a proximidade temporal (escala de tempo convencional e escala de Tempo Geológico), a proximidade temporal em relação a diferentes acontecimentos, bem como o grau de abstracção associado à compreensão destes e a importância atribuída ao conceito de tempo na aprendizagem da Geologia.

Neste artigo daremos conta dos resultados obtidos em relação aos objectivos 2 e 3 .

Tabela I. Objectivos e categorias de conteúdo onde se integram as perguntas do questionário

\begin{tabular}{|c|c|c|}
\hline OBJECTIVOS & CATEGORIAS DE CONTEÚDO & $\begin{array}{c}\text { PERGUNTASDO } \\
\text { QUESTIONÁRIO (PARTE II) }\end{array}$ \\
\hline \multirow{4}{*}{$\begin{array}{l}\text { 1. Diagnosticar as concepções dos alunos } \\
\text { acerca do conceito de tempo }\end{array}$} & 0 conceito de tempo & $1 ; 1.1 ; 2.1 ; 2.2$ \\
\hline & A idade relativa & $3 ; 4.1 ; 5 ; 6.1 ; 6.2$ \\
\hline & A idade absoluta & $4.2 ; 4.2 .1 ; 7 ; 7.1$ \\
\hline & $\begin{array}{c}\text { Os critérios usados na criação da escala de } \\
\text { Tempo Geológico }\end{array}$ & 9 \\
\hline \multirow{2}{*}{$\begin{array}{l}\text { 2. Identificar os factores que condicionam a } \\
\text { compreensão do conceito de Tempo Geológico }\end{array}$} & Proximidade temporal & $11.3 ; 11.5$ \\
\hline & 0 grau de abstracção & $11.1 ; 11.2 ; 11.8 ; 11.10$ \\
\hline $\begin{array}{l}\text { 3. Diagnosticar a importância que os alunos } \\
\text { atribuem ao "tempo" na aprendizagem da } \\
\text { Geologia }\end{array}$ & A relevância do conceito de Tempo Geológico & $8 ; 10 ; 11.4 ; 11.6 ; 11.7 ; 11.9$ \\
\hline
\end{tabular}




\section{Apresentação e análise dos resultados}

Esta secção apresenta os resultados obtidos em relação aos factores que condicionam a compreensão do conceito de Tempo Geológico e à importância que os alunos atribuem ao "tempo" na aprendizagem da Geologia. e associa o Tempo Geológico a esquemas muito complexos $(69,2 \%)$. Os dados parecem, assim, indiciar que a maior parte dos alunos considera o "Tempo Geológico" um conceito abstracto, o que condiciona a sua compreensão.

Os resultados obtidos sugerem factores que determinam a compreensão do conceito de tempo geológico são a proximidade temporal e a abstrac-

Tabela II. Distribuição da percentagem de alunos que manifestam concordância absoluta ou parcial em diferentes itens da Questão 11

\begin{tabular}{l|c}
\hline \multicolumn{1}{c|}{$\begin{array}{c}\text { Proposições } \\
\text { OTempo Geológico... }\end{array}$} & $\begin{array}{c}\text { Resultados de concordância } \\
\text { (acordo parcial } e \text { acordo absoluto) }\end{array}$ \\
\hline $11.1 \ldots$ é um conceito demasiado complexo. & $62,0 \%$ \\
\hline $11.2 \ldots$. exige números demasiado grandes. & $60,1 \%$ \\
\hline $11.3 \ldots$. relata acontecimentos cronologicamente muito distantes de mim. & $72,7 \%$ \\
\hline $11.5 \ldots$. relata fenómenos não presenciados pelo Homem. & $65,0 \%$ \\
\hline $11.8 \ldots$ exige muita memorização, associando fenómenos geológicos a uma determinada idade. & $66,3 \%$ \\
\hline $11.10 \ldots$..é apresentado em esquemas muito complexos. & $69,2 \%$ \\
\hline
\end{tabular}

\subsection{Factores que condicionam a compreensão do conceito de tempo}

Para se obterem dados que permitam explicitar as concepções dos alunos acerca dos factores que condicionam a compreensão do conceito de Tempo Geológico (Objectivo 2) criaram-se duas categorias de conteúdo, a saber: proximidade temporal (itens 11.3 ; 11.5) e grau de abstracção (itens 11.1; 11.2; 11.8; 11.10). A Tabela II apresenta dados que permitem explicitar as concepções de alunos nestas categorias.

Uma percentagem variável entre $4-7 \%$ dos inquiridos não respondeu aos itens desta questão. Cerca de $73 \%$ dos alunos considera que o Tempo Geológico relata acontecimentos cronologicamente muito distantes deles (item 11.3) e 65\% que o Tempo Geológico relata fenómenos não presenciados pelo ser humano (item 11.5). Assim, os dados obtidos indiciam que, para a maioria dos inquiridos, a proximidade temporal em relação a acontecimentos/fenómenos geológicos é um factor que condiciona a compreensão do conceito de Tempo Geológico.

Por outro lado, dos alunos que responderam ao questionário, a maior parte considera que o conceito de Tempo Geológico é demasiado complexo (62,0\%), exige a utilização de números muito grandes $(60,1 \%)$, obriga a muita memorização $(66,3 \%)$ ção do conceito, ou seja, quanto mais afastado, do ponto de vista temporal, estiver um acontecimento/fenómeno geológico mais difícil é a sua compreensão. Por outro lado, quanto mais abstracto for esse mesmo acontecimento/fenómeno mais difícil é para o aluno a sua interpretação. Além do mais, o facto de no dia-a-dia só se usarem cifras de tempo ditas humanas, ainda dificulta mais uma posição de distanciamento crítico, essencial para a compreensão de um conceito abstracto como o de Tempo Geológico. Contudo, ressaltamos o facto de os esquemas apresentados aos alunos, muitas das vezes apoiados nos manuais escolares, serem considerados complexos, o que nos lança uma orientação para a preparação de materiais escolares.

\subsection{Importância que os alunos atribuem ao "tempo" na aprendizagem da Geologia}

De modo a se obterem dados que permitam explicitar as concepções dos alunos acerca da importância que atribuem ao "tempo" na aprendizagem da Geologia (Objectivo 3), foi criada a categoria de conteúdo "relevância do conceito de Tempo Geológico". Esta categoria abrange uma questão relacionada com a escala de tempo e alguns acontecimentos geológicos (Questão 8), uma pergunta sobre a importância do Tempo Geológico para a compreensão de fenómenos e mecanismos geológicos (Questão 10) e, por último, uma questão 

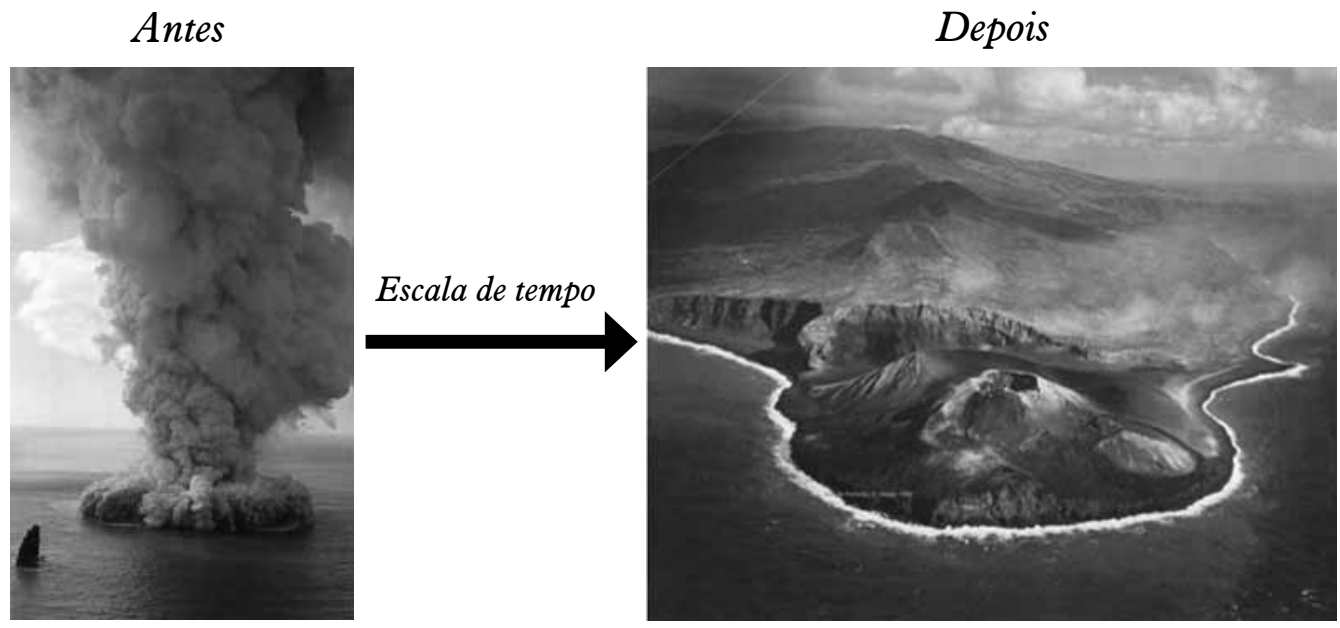

Figura 1. Formação de uma ilha vulcânica (Questão 8, acontecimento A). Fonte: questionário dos autores

para diagnosticar as concepções dos alunos acerca das dificuldades na aprendizagem do conceito de Tempo Geológico (Questão 11, itens 11.4; 11.6; $11.7 ; 11.9)$.

\subsubsection{A "escala de tempo" es "acontecimentos geológicos"}

Para que os alunos pudessem explicitar as suas concepções acerca do tempo que demoram determinados fenómenos geológicos, foi colocada uma questão de estimativa (Questão 8) que pedia para estabelecerem a associação entre uma escala de tempo com acontecimentos de natureza geológica:

- Escala de tempo: I - De um dia até um mês; II -

De um mês a um ano; III - De um ano a dez anos; IV - De dez anos a mil anos; V - De mil anos a um milhão de anos; VI - Mais de um milhão de anos;

- Acontecimentos geológicos: A - Formação de uma ilha vulcânica; B - Erosão de uma montanha; C - Actividade sísmica.

A Figura 1 apresenta as imagens associadas à formação de uma ilha vulcânica relativamente às quais os alunos deveriam estabelecer uma correspondência com uma das indicações da escala de tempo anteriormente descrita.

Tabela III. Frequências absolutas e percentagem de resposta dos alunos relativamente ao estabelecimento da correspondência entre a escala do tempo e 0 acontecimento geológico A (vulcanismo).

\begin{tabular}{l|c|c}
\hline \multicolumn{1}{c|}{ Tipo de resposta } & $\mathrm{N}$ & $\%$ \\
\hline Diferente da versão científica & 229 & 65,8 \\
\hline De acordo com a versão científica & 119 & 34,2 \\
\hline
\end{tabular}

As Tabelas III e IV apresentam as frequências absolutas e relativas (em percentagem) das respostas dos inquiridos relativamente ao tempo que foi necessário para que o vulcanismo tivesse ocorrido (acontecimento A).

Esta pergunta reuniu cerca de $20 \%$ de não respostas. A partir da análise das Tabelas III e IV pode verificar-se que apenas $34 \%$ estabelece a correspondência esperada entre a escala do tempo e o fenómeno de vulcanismo representado. A análise dos resultados obtidos evidencia que é mais elevada a percentagem dos alunos que consideram que o acontecimento A ocorreu durante um longo período de tempo, isto é, com uma duração superior a 10 anos (aproximadamente 65\%), do que a percentagem dos que entendem que o referido acontecimento geológico é rápido no tempo, durando menos de10 anos (35\%).

A Figura 2 apresenta as imagens associadas à erosão de uma montanha, relativamente às quais os alunos teriam que estabelecer uma correspondência com uma das alternativas da escala de tempo anteriormente descrita.

Tabela IV. Frequências absolutas e percentagem de resposta dos alunos relativamente à escala de tempo seleccionada para a ocorrência do acontecimento geológico A (vulcanismo).

\begin{tabular}{l|c|c}
\hline \multicolumn{1}{c|}{ Escala de tempo } & N & $\%$ \\
\hline I-De um dia até um mês & 25 & 7,1 \\
\hline II - De um mês a um ano & 44 & 12,5 \\
\hline III - De um ano a dez anos & 54 & 15,3 \\
\hline IV - De dez anos a mil anos & 77 & 21,9 \\
\hline V-De mil anos a um milhão de anos & 97 & 27,6 \\
\hline VI- Mais de um milhão de anos & 55 & 15,6 \\
\hline
\end{tabular}



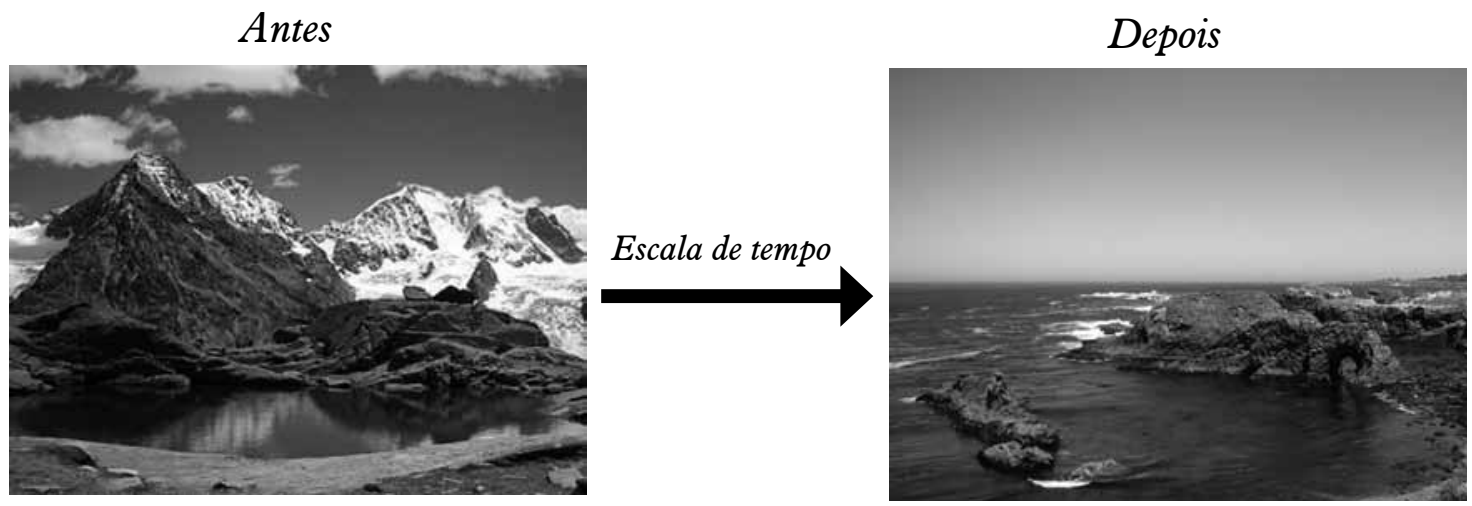

Figura 2. Erosão de uma montanha (Questão 8, acontecimento B). Fonte: questionário dos autores

Tabela V. Percentagem de resposta dos alunos relativamente ao estabelecimento da correspondência entre a escala do tempo e o acontecimento geológico B (erosão de uma montanha).

\begin{tabular}{l|c|c}
\hline Tipo de resposta & $\mathrm{N}$ & $\%$ \\
\hline De acordo com a versão científica & 222 & 64,5 \\
\hline Diferente da versão científica & 122 & 35,5 \\
\hline
\end{tabular}

Tabela VI. Frequências absolutas e relativas (em percentagem) de resposta dos alunos relativamente à escala do tempo seleccionada para a ocorrência do acontecimento geológico B (erosão de uma montanha).

\begin{tabular}{l|c|c}
\hline Escala de tempo & $\mathrm{N}$ & $\%$ \\
\hline I-De um dia até um mês & 8 & 2,3 \\
\hline II - De um mês a um ano & 22 & 6,2 \\
\hline III-De um ano a dez anos & 33 & 9,3 \\
\hline IV-De dez anos a mil anos & 69 & 19,4 \\
\hline V-De mil anos a um milhão de anos & 125 & 35,2 \\
\hline VI-Mais de um milhão de anos & 98 & 27,6 \\
\hline
\end{tabular}

antes

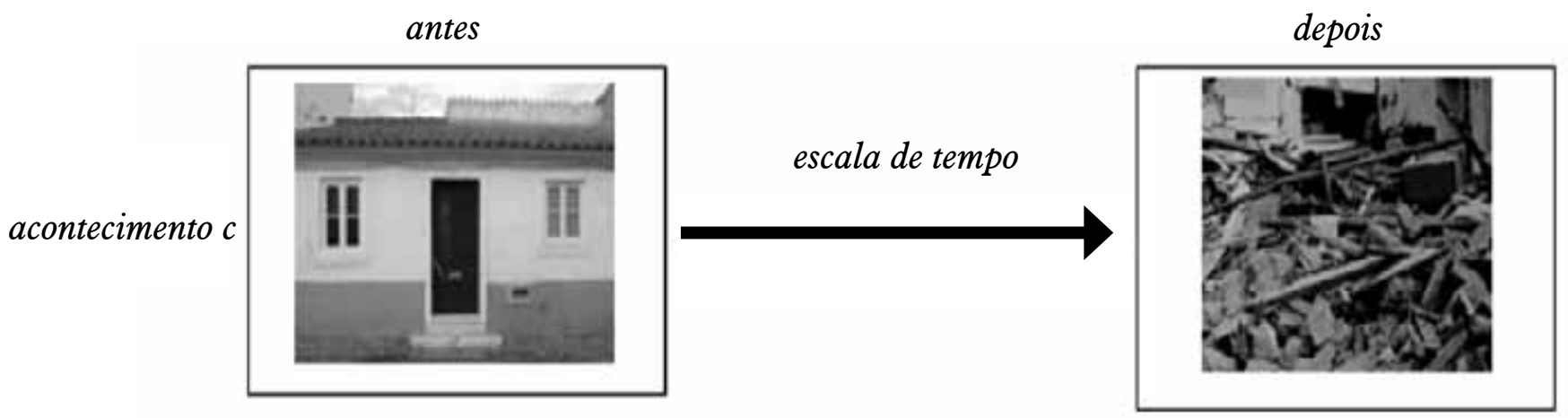

As Tabelas V e VI apresentam a frequência de resposta dos inquiridos relativamente ao tempo que foi necessário para que tivesse ocorrido a erosão de uma montanha (acontecimento B).

Seguindo a tendência anterior, cercar de $20 \%$ dos inquiridos não respondeu a esta pergunta. A análise dos dados permite constatar que aproximadamente $2 / 3$ estabelece a correspondência esperada entre a escala do tempo e a erosão de uma montanha. É maior o grupo de alunos que considera que a erosão de uma montanha ocorreu durante um período longo de tempo (duração superior a mil anos), com cerca de $63 \%$ de escolhas, que aquele que opina que o referido acontecimento geológico é rápido no tempo (duração inferior a mil anos) (37\%).

A Figura 3 apresenta as imagens associadas à actividade sísmica, relativamente às quais os alunos teriam que estabelecer correspondência com uma das alternativas da escala de tempo anteriormente considerada.

As Tabelas VII e VIII apresentam a frequência de resposta dos inquiridos relativamente ao tempo que foi necessário para que um sismo ocorresse

Figura 3. Actividade sísmica (Questão 8, acontecimento C). Fonte: questionário dos autores 
Tabela VII. Frequências absolutas e percentagens de resposta dos alunos relativamente à correspondência entre a escala do tempo e o acontecimento geológico C (sismo)

\begin{tabular}{l|c|c}
\hline \multicolumn{1}{c|}{ Tipo de resposta } & N & $\%$ \\
\hline De acordo com a versão científica & 235 & $66 \%$ \\
\hline Diferente da versão científica & 121 & $34 \%$ \\
\hline
\end{tabular}

Tabela VIII. Frequências de resposta dos alunos relativamente à escala do tempo seleccionada para a ocorrência do acontecimento geológico C (sismo)

\begin{tabular}{l|c|c}
\hline Escala de tempo & $\mathrm{N}$ & $\%$ \\
\hline I-De um dia até um mês & 235 & $66 \%$ \\
\hline II-De um mês a um ano & 36 & $10,1 \%$ \\
\hline III - De um ano a dez anos & 31 & $8,7 \%$ \\
\hline IV - De dez anos a mil anos & 33 & $9,3 \%$ \\
\hline V-De mil anos a um milhão de anos & 12 & $3,4 \%$ \\
\hline VI-Mais de um milhão de anos & 9 & $2,5 \%$ \\
\hline
\end{tabular}

(acontecimento $\mathrm{C}$ ).

Cerca de 17,6\% dos inquiridos não respondeu a esta questão. A leitura da Tabela VIII permite verificar que mais de $50 \%$ estabelece a correspondência esperada entre a escala do tempo e a actividade sísmica. A percentagem dos alunos que considera que a actividade sísmica (acontecimento C) ocorreu durante um período curto de tempo (duração inferior a um mês) é superior àquela dos alunos que consideram que o referido acontecimento geológico é demorado no tempo (duração superior a um mês) (34\%).

A interpretação destes dados permite aproximar-nos das concepções dos alunos acerca do tempo que consideram que envolvem determinados acontecimentos geológicos (vulcanismo, erosão de uma montanha e actividade sísmica) e extrair as seguintes evidências:

a) Existe um reconhecimento explícito da maioria dos alunos, acerca do facto de considerarem que os sismos são acontecimentos geológicos que ocorrem num curto período de tempo (66\%) e que a erosão de uma montanha é, temporalmente, um acontecimento que demora mais tempo. Possivelmente, a ocorrência de um sismo, devido à sua notoriedade em termos de comunicação social torna mais fácil classificá-lo como um fenómeno geológico rápido. Ou seja, há como que ajudas sociais que permitem os alunos classificar, na sua maioria, este acontecimento de forma correcta. A questão da erosão da montanha é explicada aos mais pequenos como um fenómeno muito lento provocado pelas águas das chuvas. Assim, estes dois acontecimentos geológicos são compreendidos pela maioria dos alunos, no que respeita à sua percepção temporal. Contudo, não se pode descurar os alunos que não responderam correctamente. Teremos em conta estas considerações na elaboração dos materiais didácticos;

b) Os alunos revelam mais dificuldades na associação correcta do tempo que demoram acontecimentos geológicos lentos (64,5\% de respostas de acordo com a versão científica) do que na associação correcta que demoram acontecimentos geológicos rápidos (66\%). Este facto patente na nossa análise de resultados pode estar relacionado com o facto de ser muito difícil e complexo, para alunos cujo pensamento formal ainda se está a desenvolver, de se libertarem de conceitos práticos para passarem a conceitos abstractos;

c) Quanto ao vulcanismo, os alunos revelam dificuldades em estabelecer a associação esperada (34\%), uma vez que consideraram que o referido fenómeno ocorreu durante um intervalo longo de tempo (duração superior a 10 anos) (65\%). Perante estes resultados podemonos questionar se a maioria dos alunos não considerou todo o processo de formação de um vulcão. Se tal, então esta resposta levanta-nos a pertinência de uma reestruturação da questão em si. Se os alunos não consideraram o processo de formação do vulcão e consideraram que os fenómenos eruptivos são muito morosos, então este é um ponto a tomar em consideração na elaboração dos materiais didácticos;

d) A ausência de resposta, entre 17-20\%, conduz-nos a pensar que esta pergunta oferece dificuldades de alguma natureza, necessitando de ser reformulada para integrar o questionário final.

\subsubsection{Importância do Tempo Geológico para a compreensão de fenómenos e mecanismos geológicos}

De modo a se poder conhecer a opinião dos alunos relativamente à pertinência que atribuem ao Tempo Geológico para a compreensão de fenó- 
Tabela IX. Distribuição das percentagens de alunos que manifestam concordância absoluta ou parcial nos diferentes itens da Questão 10

\begin{tabular}{l|c}
\hline \multicolumn{1}{c|}{$\begin{array}{c}\text { Proposições } \\
\text { OTempo Geológico... }\end{array}$} & $\begin{array}{c}\text { Resultado de concordância } \\
\text { (acordo parcial e acordo } \\
\text { absoluto) }\end{array}$ \\
\hline $10.1 \ldots$ permite compreender a tectónica de placas. & $63,9 \%$ \\
\hline $10.2 \ldots$ permite contabilizar a precipitação de uma determinada região. & $53,9 \%$ \\
\hline $10.3 \ldots$ permite compreender o desaparecimento dos dinossauros. & $73,1 \%$ \\
\hline $10.4 \ldots$ não permite compreender a evolução da vida na Terra. & $41,6 \%$ \\
\hline $10.5 \ldots$ permite explicar a formação de montanhas. & $67,5 \%$ \\
\hline $10.6 \ldots$ permite medir a variação da temperatura diária de uma determinada região. & $55,6 \%$ \\
\hline $10.7 \ldots$ permite prever a erupção de um vulcão. & $59,7 \%$ \\
\hline $10.8 \ldots$ permite explicar a formação do oceano Atlântico. & $64,8 \%$ \\
\hline $\begin{array}{l}10.9 . \ldots \text { não permite explicar a diferença da } \\
\text { biodiversidade existente na Austrália, relativamente aos outros continentes. }\end{array}$ & $43,6 \%$ \\
\hline $10.10 \ldots$. não permite prever a ocorrência de um sismo. & $56,6 \%$
\end{tabular}

menos e mecanismos geológicos, formulou-se a Questão 10, onde foi pedido o grau de concordância relativamente a um conjunto de afirmações. Os dados obtidos permitiram construir a Tabela IX.

Esta questão não foi respondida por 4-6\% dos inquiridos. A leitura da Tabela permite identificar que mais de $40 \%$ dos alunos manifesta um desacordo parcial ou absoluto relativamente ao facto de o Tempo Geológico não permitir a compreensão da evolução da vida na Terra (item 10.4), nem explicar a biodiversidade existente na Austrália, relativamente a outros continentes (10.9). Por outro lado, mais de $50 \%$ manifesta acordo parcial ou absoluto ao reconhecer o contributo que o conceito de Tempo Geológico pode dar para a compreensão de diversos fenómenos e mecanismos geológicos (itens 10.1, 10.3, 10.5, 10.7 e 10.8). Uma percentagem semelhante de respostas leva a perceber que o conceito de Tempo Geológico não permite prever a ocorrência de um sismo (item 10.10), mas pode dar um contributo importante para a contabilização da precipitação (item 10.2) e da variação de temperatura de uma determinada região (item 10.6).

A análise e interpretação dos dados obtidos na Questão 10 permite caracterizar algumas concepções dos alunos relativamente à importância que atribuem ao Tempo Geológico para a compreensão de fenómenos e de mecanismos geológicos e extrair as seguintes evidências: a) O Tempo Geológico é importante para compreender fenómenos e mecanismos geológicos diversificados (tectónica de placas, desaparecimento dos dinossauros, formação de montanhas, entre outros). Desta forma, podemos considerar que os alunos associam fenómenos geológicos com morosidade geológica, em termos globais;

b) Os alunos revelam dificuldades na utilização do conceito de tempo geológico, uma vez que consideram que este é importante para compreender fenómenos geográficos, como a contabilização da precipitação e a variação de temperatura de uma dada região. Possivelmente, devido ao termo "tempo" que em linguagem corrente designa o clima de uma região, os alunos consideraram esses fenómenos, o que lhes terá suscitado uma confusão conceptual atendendo a formulação da questão;

c) O Tempo Geológico permite compreender a evolução da vida na Terra e permite explicar a diferença de biodiversidade existente na Austrália, relativamente aos outros continentes. Neste ponto, salientamos a compreensão dos alunos face ao conceito da evolução das espécies, abordada para o género Homo na disciplina de História e que notoriamente transferiram para a de Ciências Naturais, em concreto para o questionário. 
Tabela X. Distribuição da percentagem de alunos que manifestam concordância absoluta ou parcial em diferentes itens da Questão 11

\begin{tabular}{l|c}
\hline \multicolumn{1}{c|}{$\begin{array}{c}\text { Proposições } \\
\text { OTempo Geológico... }\end{array}$} & $\begin{array}{c}\text { Resultado de concordância } \\
\text { (acordo parcial } \text { e acordo absoluto) }\end{array}$ \\
\hline $11.4 \ldots$ dificulta a compreensão de fenómenos geológicos (ex. formação e erosão de montanhas, ...). & $56,1 \%$ \\
\hline $11.6 \ldots$ é dispensável na aprendizagem da Geologia. & $45,9 \%$ \\
\hline $11.7 \ldots$ dificulta a compreensão da história da Terra. & $54,9 \%$ \\
\hline $11.9 \ldots$ ajuda a compreender os acontecimentos da pré-história. & $74,0 \%$ \\
\hline
\end{tabular}

\subsubsection{Dificuldades sentidas na aprendizagem do conceito de Tempo Geológico}

De modo a obterem-se dados que permitam diagnosticar as concepções dos alunos relativamente às dificuldades que sentem na aprendizagem do conceito Tempo Geológico formulou-se a Questão 11, onde era solicitado que se assinalasse o grau de concordância relativamente a um conjunto de afirmações (11.4, 11.6, 11.7 e 11.9). Os dados obtidos permitiram construir a Tabela $\mathrm{X}$.

Uma percentagem variavel de entre 5-6\% dos inquiridos não respondeu a esta questão. $\mathrm{Na}$ análise das respostas a esta pergunta foi possível identificar três tipos de posições. Pouco mais de metade dos alunos reconhece que o conceito de tempo geológico dificulta tanto a compreensão de fenómenos geológicos tanto a compreensão da história da Terra. Por outro lado, cerca de $46 \%$ opina que o Tempo Geológico é dispensável na aprendizagem da Geologia e que ajuda a compreender os acontecimentos da pré-história (74\%).

A análise e interpretação dos dados obtidos neste estudo exploratório permitem extrair os seguintes indicadores:

a) Os sismos são conhecidos por acontecimentos geológicos que ocorrem num curto período de tempo, demorando mais tempo o vulcanismo e a erosão de uma montanha;

b) Há mais dificuldades na associação correcta do tempo que demoram acontecimentos geológicos lentos (ex.: erosão de uma montanha) do que na associação correcta de acontecimentos geológicos rápidos (tremor de terra);

c) Reconhece-se a relevância do Tempo Geológico para a compreensão de fenómenos e mecanismos geológicos. Valoriza-se a importância do conceito de Tempo Geológico na compreensão de fenómenos geológicos que ocorreram no passado na Terra (ex.: tectónica de placas, desaparecimento dos dinossauros, formação de montanhas, formação do oceano Atlântico). Porém, metade dos alunos considera que o Tempo Geológico não é importante na previsão da ocorrência de acontecimentos relacionados com a história da Terra;

d) Existem dificuldades na compreensão do conceito de Tempo Geológico. Considera-se que é um conceito complexo, que dificulta a compreensão de fenómenos geológicos e da história da Terra, sendo, por isso, considerado dispensável na aprendizagem da Geologia. Dado que não existe clareza nos alunos do conceito de Tempo Geológico, este é referido como importante para ajudar a compreender os acontecimentos da pré-história.(74\%)

e) Os indicadores obtidos permitem reconhecer que os alunos atribuem importância ao conceito de Tempo Geológico na aprendizagem da Geologia, apesar de não existir uma clarificação correcta do próprio conceito, o que leva a que o associem a fenómenos que não estão relacionados com acontecimentos geológicos.

Em função do exposto, considera-se que se torna necessário ajudar os alunos a clarificar o conceito de Tempo Geológico e a valorizar a sua importância na compreensão da história da Terra, sendo necessário investir na concepção e implementação de materiais didácticos curriculares que integrem actividades práticas diversificadas (de pesquisa, laboratoriais, experimentais, de campo, entre outras), que promovam a compreensão da complexidade dos fenómenos e da sequência temporal de alguns acontecimentos geológicos. Também será necessário que esta temática passe a ser abordada e aprofundada na formação contínua de professores de Geologia, dado que a abordagem curricular de conceitos complexos, como é o caso 
do conceito de Tempo Geológico, não se coaduna com perspectivas redutoras do ensino da Geologia. É importante não cair na tentação de, à custa da simplificação da realidade a explicar, induzir a aprendizagem com erros científicos.

\section{Considerações finais}

A vastidão do tempo em que decorrem os processos geológicos está completamente fora do tempo da experiência vivenciada pela humanidade. Fazer uma ponte entre as experiências de tempo vividas pelos alunos, onde estes convivem com escalas de tempo que incorporam o momento, o dia, o ano ou o período de uma geração ou século, até aquelas que integram situações que ocorreram no planeta Terra desde há milhares de milhões de anos é, reconheça-se, uma tarefa tão desafiante como cognitivamente exigente, requerendo atenção e preparação cuidadas por parte dos intervenientes. Não deve deixar de ser enfatizado que o que está em causa é a abordagem de uma temática bem complexa, procurando relações entre os domínios da filosofia e da ciência. Tal temática vem sendo objecto de uma aprofundada e continuada discussão da qual, afinal, emerge um conjunto alargado de questões e uma atitude eminentemente questionante (Pereira 1998).

Todo esse processo necessita de ser articulado e continuado nos distintos níveis de ensino, até porque é pacífico, do ponto de vista da ciência, que a imensidão do tempo é fundamental para o desenvolvimento do pensamento geológico, já que facilita a compreensão da acção que integra alguns dos imperceptíveis processos geológicos e as suas consequências ao nível das mudanças gigantescas que têm ocorrido no planeta Terra. A importância da compreensão do tempo geológico aplica-se, também, ao cidadão contemporâneo, na medida em que o ser humano necessita face aos processos naturais para bem delimitar o alcance e os risco de desastre, em potencial, das suas acções. Do ponto de vista epistemológico, e não só, aceita-se que para entender a brevidade da existência humana relativamente à vastidão da história da Terra se requer innovation in our sense of reality (Frodeman 2003).

Do ponto de vista educacional, a análise reflexiva dos dados obtidos neste diagnóstico de concepções de alunos acerca dos factores que condicionam a compreensão deste conceito crucial de tempo geológico, bem como da importância que lhe é atribuída na aprendizagem da Geologia, permitenos extrair os seguintes indicadores:

- Os factores que condicionam a compreensão do conceito de tempo geológico são a proximidade temporal e a abstracção do próprio conceito;

- Existem maiores dificuldades na associação correcta do tempo que demoram acontecimentos geológicos lentos relativamente à duração de fenómenos geológicos de curta duração;

- É valorizada a importância do conceito de Tempo Geológico na aprendizagem da Geologia, apesar de não existir acerca dele uma perspectiva adequada. Em consequência, associa-se Tempo Geológico a fenómenos que não estão relacionados com acontecimentos geológicos;

- As dificuldades sentidas na compreensão do conceito de Tempo Geológico recaem no facto de ser um conceito complexo, que dificulta a compreensão de fenómenos geológicos e da história da Terra, sendo, por isso, considerado dispensável na aprendizagem da Geologia. Aliás, o conceito é ainda considerado relevante para ajudar a compreender os acontecimentos da pré-história.

Do ponto de vista dos autores, os indicadores emergentes desta primeira fase da investigação reforçam a relevância do projecto inicialmente referido e no qual este estudo se integra. À natureza do tempo corresponde um efectivo grau de complexidade e, portanto, é indispensável que a abordagem curricular de temáticas como, por exemplo, a História da Terra, seja desenvolvida com particular atenção por parte dos professores. Por isso, consideramos ser crucial aprofundar o trabalho ao nível da formação de professores sob uma perspectiva sistémica, em que a formação inicial e contínua se articulem entre si, como um todo coerente e numa lógica de aprendizagem ao longo da vida.

$\mathrm{Na}$ sequência do que vem sendo apontado relativamente à temática muito concreta do tempo, a formação de professores responsáveis pelo ensino de conteúdos do âmbito das Geociências deve contemplar, por um lado, o aprofundamento científico dos saberes académicos numa dimensão integrada com outras áreas, de forma a proporcionar uma perspectiva holística. Por outro, a referida formação não pode prescindir de promover a reflexão e discussão entre os docentes acerca das estratégias normalmente usadas na abordagem 
da temática do Tempo Geológico, tendo sempre presente que esta se não coaduna com perspectivas redutoras do ensino das Geociências. Exigese, assim, o desenvolvimento de uma visão mais multi-interdisciplinar e pluridimensional, onde, por exemplo, a Ciência e a Filosofia dêem suporte a um pensamento holístico mais enriquecedor culturalmente e, portanto, enriquecedor da própria literacia científica do cidadão.

Uma das vertentes da estratégia de formação passa, necessariamente por investir na concepção, organização e implementação de materiais didácticos pelos professores que integrem indicadores emergentes da investigação, por meio de actividades diversificadas - de pesquisa, laboratoriais, experimentais, de campo, entre outras, e da sua aplicação supervisionada por didactas e por pares. Estas medidas deverão contribuir para o desenvolvimento do sentido crítico e para uma atitude de questionamento sistemático, facilitando a compreensão da natureza dos fenómenos temporais, bem como a sequência de alguns acontecimentos geológicos.

Um contributo que os autores pretendem dar para a investigação em didáctica das ciências passa, exactamente, pelo desenvolvimento futuro de materiais didácticos, devidamente validados, que ajudem os alunos a compreender a complexidade inerente ao conceito do Tempo Geológico, valorizando a sua importância na aprendizagem da Geologia e no seu próprio crescimento pessoal.

\section{Referências bibliográficas}

Bonito J., Medina J., Morgado M., Rebelo D., Monteiro G., Louro M., Martins, L., Marques L. 2010. La naturaleza del tiempo y su complejidad: el caso del tiempo geológico - implicaciones educativas. dyna,169(78),247-257.

Carrière, J. C. 1999. As perguntas da esfinge. In: C. David, Lenoir F., Tonnac J.-P. orgs. O fim dos tempos. Lisboa: Terramar.

Coveney P., Highfield R. 1992. La flecha del tiempo. Barcelona: Plaza y Janés.

Dodick J., Orion N. 2003. Measuring student understanding of geological time. Science Education, 87:708-731.

Einstein A. 2000. Relativity. The special and general theory. New York: Bartleby.

Escribano Ródenas M. 2008. La medida del tiempo geológico: un reto en secundaria. Actas del XV Simposio sobre Enseñanza de la Geologia. Madrid: Instituto Geológico y Minero de España. P. 119127.
Freud S. 1974. O inconsciente. Rio de Janeiro: Imago.

Frodeman R. 2003. Geo-Logic. Breaking ground between philosophy and the Earth sciences. New York. State Univ. of New York Press.

Hawking S. 1988. Breve história do tempo. Lisboa: Gradiva.

Klein E. 2007. O tempo de Galileu a Einstein. Lisboa. Caleidoscópio Ed.

Marques L., Thompson D. 1997. Portuguese students' understanding at age 10/11 and 14/15 of the origin and nature of the Earth and the development of Life. Research in science and technological education, 15:29-51.

Pardal L., Correia E. 1995. Métodos e técnicas de investigação social. Porto: Areal Editores.

Pereira P. 1988. O espaço e o tempo. Intraligações. Lisboa: Fim de Século Edições.

Prigogine I. 1990. O nascimento do tempo. Lisboa: Edições 70.

Santo Agostinho 1990. Confissões. 12. ${ }^{\mathrm{a}}$ ed. Braga: Livraria do Apostolado da Imprensa.

Trend R. 2005. Individual, situational and topic interest in geoscience among 11-and 12-year-old children. Research Papers in Education, 20(3):271302.

Yousef M. H. 2008. Ibn Arab̂̀ - Time and cosmology. London: Routledge. 